\title{
A DEMAND-ORIENTED INDUSTRY-SPECIFIC VOLATILITY SPILLOVER NETWORK ANALYSIS OF CHINA'S STOCK MARKET AROUND THE OUTBREAK OF COVID-19
}

\author{
Fu Qiao ${ }^{1+}$ \\ Yan Yan $^{2}$
}

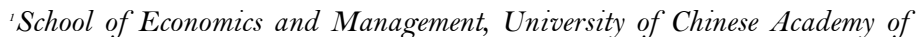 \\ Sciences, Beijing, China. \\ Email:qiaofu17@mails.ucas.edu.cn Tel: +8613051361751 \\ ${ }^{2}$ Research Center on Fictitious Economy \& Data Science, Chinese Academy of \\ Sciences, Beijing, China. \\ Email:songxueyany@sohu.com Tel:+8613810405139
}

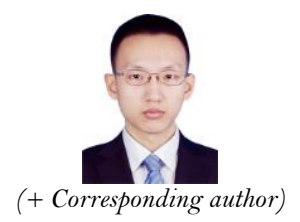

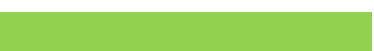

Article History

Received: 8 October 2020 Revised: 26 October 2020 Accepted: 6 November 2020 Published: 23 November 2020

\section{Keywords}

Volatility spillover network BEKK-GARCH

Industry classification

China's stock market

Demand

COVID-19.

\section{JEL Classification:} C58; G10.

\begin{abstract}
Using a carefully selected industry classification standard, we divided 102 industry security indices in China's stock market into four demand-oriented sector groups and identified demand-oriented industry-specific volatility spillover networks. The demandoriented concept is a new way in which to reconstruct the structure of the networks. Analyzing networks from a demand-oriented perspective can improve the understanding of the change in economic demand, especially when the macroeconomy is dramatically influenced by exogenous shocks, such as those due to the outbreak of COVID-19. At the beginning of the outbreak, spillover effects from industry indices of sectors meeting the investment demand to those meeting the consumption demands rose significantly in China's stock market. However, these spillover effects declined after the outbreak containment in China appeared to be effective. In addition, some service sectors, including utility, transportation and information services, have played increasingly important roles in the networks of industry-specific volatility spillovers since the COVID-19 outbreak. The efforts to contain the outbreak, led by the Chinese government, have been successful and work resumption has been organized with high efficiency. First, the risk of investment demand has therefore been controlled and eliminated relatively quickly. Second, the intensive use of non-pharmaceutical interventions (NPIs) has led to supply restrictions in services in China, which will still be a potential threat to economic recovery in the next stage.
\end{abstract}

Contribution/Originality: This is one of very few studies that has investigated the volatility spillovers in the industry-specific networks of China's stock market during the COVID-19 pandemic. The paper's primary contribution is finding the critical role that the service sectors play in the industry-specific network after the COVID-19 outbreak was contained.

\section{INTRODUCTION}

Frequently in the stock market, fluctuations in stock prices initially occur in companies belonging to one sector and gradually spread to other sectors. China's stock market has become the second largest in the world. Up to January 2020, 3780 companies from a variety of sectors listed their shares on China's stock market, which had a total value of more than 60.38 billion RMBs (approximately equal to 8.65 trillion US dollars). Thus, it is important 
for both investors and policymakers around the world to understand the complex linkage effects shown by fluctuations in the stock prices (or yields) of companies in different sectors in China's stock market.

One of the typical measurements of the linkage characteristics between different variables is the spillover effect, which can be measured by using the generalized autoregressive conditional heteroskedastic (GARCH) family of models (such as the BEKK-GARCH and DCC-GARCH models) or the variance decomposition model under the vector autoregression (VAR) framework (Diebold \& Yilmaz, 2012; Jiang, Jiang, Nie, \& Mo, 2019; Singh, Kumar, \& Pandey, 2010).

Studies on industry-specific volatility spillover networks have highlighted the measurement of the linkage level. These studies were initially motivated by finding the arbitrage opportunities between upstream and downstream industry sectors in the supply chain. In addition, studies, such as those by Yarovaya, Brzeszczyński, and Lau (2016) and Yin, Liu, and Jin (2020), further found that volatility spillovers also exist between industry sectors without a direct input-output relationship. However, the existing literature does not answer the question of how industry-specific volatility spillover networks reflect economic demand and its changes. We believe that there are two reasons for this. First, it is more difficult to provide a proper explanation for the findings in analyses on industry-specific volatility spillover networks than those done across countries or regions. Part of the detected spillovers in the networks might match economic theory, such as the spillovers between the energy and finance sectors, or those between the transportation and consumption sectors (Gonzalez-Navarro \& Quintana-Domeque, 2016; Singh, Nishant, \& Kumar, 2018). However, the rest of the spillovers might not be properly explained. Second, some scholars have criticized the arbitrariness when selecting industry classification standards. Mateus, Chinthalapati, \& Mateus (2017) pointed out that the industry classification standard should be cautiously selected depending on the research targets. When necessary, self-built industry indices should also be used for pursuing more meaningful numerical results and theoretical implications.

Some early studies on this topic showed that exogenous shocks to the macroeconomy of a country do not lead to fluctuations in the prices of all securities in the country at the same time (Campbell, Lettau, Malkiel, \& Xu, 2001; Ewing, Forbes, \& Payne, 2003; Wang, 2010). Inspired by these studies, we further considered how the demand structure influences industry-specific spillover networks. The demands of a country mainly comprise consumption, investment and export. One of the critical factors of the profit and asset price of companies is whether or not their goods or services successfully meet a part of the demand (Acemoglu \& Guerrieri, 2008). The influence of exogenous shocks on economic demand should, therefore, be reflected in the structural change in the industry-specific volatility spillover networks.

To highlight the economic demand structure, we chose the industry classification standard constructed by SWS Research Co., Ltd., which is the largest securities research institute in Mainland China ${ }^{1}$. Using the SWS standard, we identified the GARCH-BEKK-based demand-oriented industry-specific volatility spillover networks of China's stock market. Each node in the networks represents a level 2 industry securities index in the SWS industry list. We chose the minute-per-minute return data between January 2 and March 20, 2020 for 102 SWS industry indices as the sample. In this period, the exogenous shock of the outbreak of COVID-19 dramatically changed economic demand in China.

\footnotetext{
${ }^{1}$ Most of the studies on industry-specific spillover network analysis of China's stock market chose the industry classification standard created by China Securities Index (CSI) Co., Ltd. (the CSI standard). However, the CSI standard cannot match all research targets. According to the CSI standard, the categories of "consumption goods" and "capital goods" are not parallel with each other. Companies supplying goods or services for consumption demands belong to the "consumer staples" or "consumer discretionary" sectors (level-1 categories). In contrast, companies meeting the investment demand cannot be classified as a sector. They can be classified only as an industry group, "capital goods" (a level-2 category), which belongs to the industrial sector. Thus, the spillover network analysis using the CSI standard cannot reflect the economic demand and its change correctly. The SWS standard divided the industry sectors into four sector groups, each of which is homogenous in meeting specific economic demand.
} 
Recent studies have reported the influence of COVID-19 on both the macroeconomies and financial markets of different countries or regions. Some of them focused on the impact of the disease on the financial market in a single country, or the overall impact on global financial markets (Gupta \& Chatterjee, 2020; Lewis, 2020; Procacci, Phelan, \& Aste, 2020). Furthermore, according to Huang et al. (2020), industry-specific networks were identified based on macroeconomic data rather than data from financial markets. These studies provided us with a good incentive to design further research to illustrate how industry-specific volatility spillover networks can reflect change in economic demand.

Our study extends the literature and contributes the following:

(1) From the perspective of demand, we developed a new idea for reconstructing the structure of the industryspecific spillover network. By reorganizing the industry securities indices into demand-oriented sector groups, a better linkage between the theories of macroeconomics and the industry-specific network analysis of the financial market can therefore be obtained.

(2) We provided an early report of the structural change in the industry-specific volatility spillover networks of China's financial market around the outbreak of COVID-19. We further analyzed how the changes in this network reflected the changes in economic demand as a result of the disease.

(3) A list of new economic implications was found from the numerical results. First, during the entire study period, there were stable spillovers from the capital goods sector group to the consumption goods sector group. The spillovers from the capital goods and equipment manufacturing sector groups, which represent the demand for investment, to other sector groups rose significantly at the beginning of the COVID-19 outbreak. However, these spillovers declined approximately one month later. Second, the level of spillovers from the unclassified services sector group was continuously rising during the whole study period. This rising trend reflected that the intensive use of non-pharmaceutical interventions (NPIs) (Lai et al., 2020) in China caused supply restrictions to services and, therefore, had an overall impact on all types of demand.

The next section introduces the data selection and preprocessing strategies used, section 3 discusses the methodology, section 4 presents the empirical study of the demand-oriented industry-specific volatility spillover network analysis based on the SWS industry classification standard, section 5 presents a further discussion, and section 6 concludes the study.

\section{DATA}

The study period was from January 2 to March 20, 2020. Considering the size of the spread and the progress in containing COVID-19 both inside and outside China, we divided the study period into three subperiods. Period 1 is between January 2 and January 23, 2020; period 2 is between February 3 and February 28, 2020, and period 3 is between March 2 and March 20, 2020. Periods 1, 2 and 3 have 16, 20 and 15 trading days, respectively. ${ }^{2}$

We chose the SWS standard as the industry classification standard. According to this standard, securities in China's stock market are divided into 28 sectors, which are further divided into 104 industry groups. As shown in Table 1, the SWS standard integrated the sectors into four demand-oriented sector groups.

\footnotetext{
2 As early as December 27, 2019, the local government of Wuhan began to report patients with "unknown pneumonia", and made public health responses to the infection. As of January 20, 2020, the Chinese government began to implement nationwide containment of COVID-19. On January 31, 2020, the World Health Organization (WHO) declared COVID-19 a public health emergency of international concern (PHEIC). To guarantee that all patients could be treated, the Chinese government covered all bills of pharmaceutical treatment via their budgets. In addition, to reduce the size of the pandemic, multiple non-pharmaceutical interventions (NPIs) were used by the Chinese government, including intercity travel restrictions, the early identification and isolation of suspected ill people and contact restriction measures. As a result, the outbreak was preliminarily contained in China by the end of February. Since March 18, 2020, the number of new patients has remained under ten per day. However, COVID-19 spread outside of China. On February 29, 2020, the WHO increased the assessment of the risk of spread to "very high" at a global level.
} 
Table 1. Official categories of sector groups and sectors according to SWS industry classification standard.

\begin{tabular}{|c|c|c|}
\hline $\begin{array}{l}\text { Sector Group } \\
\text { (Abbreviation) }\end{array}$ & Sector & $\begin{array}{l}\text { The last four digits of the relative industry group (evel- } \\
2 \text { category) indices codes }\end{array}$ \\
\hline \multirow{8}{*}{$\begin{array}{l}\text { Consumption goods } \\
(\mathrm{Cg})\end{array}$} & $\begin{array}{l}\text { Agriculture, forestry, } \\
\text { husbandry and fishery }\end{array}$ & $\begin{array}{l}1011,1012,1013,1014 \\
1015,1016,1017,1018\end{array}$ \\
\hline & Household appliances & 1111,1112 \\
\hline & Food and beverage & 1123,1124 \\
\hline & Apparel and textiles & 1131,1132 \\
\hline & Light manufacturing & $1141,1142,1143$ \\
\hline & $\begin{array}{l}\text { Biochemical and } \\
\text { pharmaceuticals }\end{array}$ & $1151,1152,1153,1154,1155,1156$ \\
\hline & Leisure Services & $1211,1212,1213,1214$ \\
\hline & Commercial trade & $1202,1203,1204,1205$ \\
\hline \multirow{6}{*}{ Capital goods (Kg) } & Mining & $1021,1022,1023,1024$ \\
\hline & Chemicals & 1032, 1033, 1034, 1035, 1036, 1037 \\
\hline & Non-ferrous metal & $1051,1053,1054,1055$ \\
\hline & $\begin{array}{l}\text { Construction and } \\
\text { decoration }\end{array}$ & $1711,1712,1713$ \\
\hline & Building materials & $1721,1722,1723,1724,1725$ \\
\hline & Ferrous metal & 1041 \\
\hline \multirow{6}{*}{$\begin{array}{l}\text { Equipment } \\
\text { manufacturing }(\mathrm{Ke})\end{array}$} & Machinery & $1072,1073,1074,1075,1076$ \\
\hline & Electronic components & $1081,1082,1083,1084,1085$ \\
\hline & Electrical equipment & $1731,1732,1733,1734$ \\
\hline & Motor & $1092,1093,1094,1881$ \\
\hline & $\begin{array}{l}\text { Defense and military } \\
\text { industry }\end{array}$ & $1741,1742,1743,1744$ \\
\hline & Information facilities & 1222,1223 \\
\hline \multirow{7}{*}{$\begin{array}{l}\text { Unclassified services } \\
\text { (Us) }\end{array}$} & Utilities & $1161,1162,1163,1164$ \\
\hline & Transportation & $1171,1172,1173,1174,1175,1176,1177,1178$ \\
\hline & Real estate & 1181,1182 \\
\hline & Bank & 1192 \\
\hline & $\begin{array}{l}\text { Non-bank financial } \\
\text { services }\end{array}$ & $1191,1193,1194$ \\
\hline & Information services & 1222,1223 \\
\hline & Media & $1751,1752,1761$ \\
\hline
\end{tabular}

Source: Wind Financial Database.

Notes 1: The conglomerates sector consists of listed companies with diversified businesses in which no single business is dominant. Although as a sector vertex in the sector-specific spillover network, the SWS conglomerates sector index belongs to none of the sector groups. 2: The codes of industry group indices (level 2 categories of industry classification system) consist of six digits in which the first two digits are " 80 ".

As a supplement of Table 1, we listed the names and the codes of all industry group indices according to the SWS standard in the Appendix A. In addition, because the level 3 categories (industry) were not mentioned in this paper, we will refer to the industry group securities index as the "industry securities index" in the following sections.

The minute-per-minute data of the closing prices of 102 SWS industry securities indices are available from the Wind Financial Database. We calculated the $\log$ return of $P_{i, t}$, which is the price of index $\mathrm{i}$ at moment $\mathrm{t}$, as $r_{i, t}=\ln \left(P_{i, t}\right)-\ln \left(P_{i, t-1}\right)$. We obtained $r_{i}=\left\{r_{i, t}\right\}, t \in\{1,2, \ldots, T\}$ as the log return series of index i. The comprehensive descriptive statistics of the log return series of all industry securities indices in different periods can be found in the Appendix B.

\section{METHODOLOGY}

\subsection{BEKK-GARCH-Based Volatility Spillover Network}

The BEKK-GARCH model was proposed by Engle and Kroner (1995). The economic implication of the model is attractive because its parameters are able to detect the spillover effect between variables. Considering the time 
series $r_{i}=\left\{r_{i, t}\right\}, t \in\{1,2, \cdots, T\}$ and $r_{j}=\left\{r_{j, t}\right\}, t \in\{1,2, \ldots, T\}$, a bivariate BEKK-GARCH model is required to test the spillover effect between them. This bivariate model consists of a mean equation and a variance equation. According to Kang, Cheong, and Yoon (2013) and Lin, Wesseh Jr, and Appiah (2014), the lag order of both equations can be set as 1. The mean equation of the bivariate BEKK-GARCH model is shown in Equation 1:

$$
\left[\begin{array}{l}
r_{i, t} \\
r_{j, t}
\end{array}\right]=\left[\begin{array}{l}
\mu_{i} \\
\mu_{j}
\end{array}\right]+\left[\begin{array}{ll}
\varphi_{i i} & \varphi_{i j} \\
\varphi_{j i} & \varphi_{j j}
\end{array}\right]\left[\begin{array}{l}
r_{i, t-1} \\
r_{j, t}, 1
\end{array}\right]+\left[\begin{array}{l}
\varepsilon_{i, t} \\
\varepsilon_{j, t}
\end{array}\right]
$$

where $\mu_{i}, \mu_{j}, \varphi_{i i}, \varphi_{i j}, \varphi_{j i}$ and $\varphi_{j j}$ are the parameters to be estimated, and $\varepsilon_{i, t}$ and $\varepsilon_{j, t}$ are residuals. They are also

called innovations, which represent the influence of the new information generated at moment $t$.

The variance model is shown below in Equation 2:

$$
H_{t}=C^{\prime} C+A^{\prime} \varepsilon_{t-1} \varepsilon_{t-1}^{t} A+B^{\prime} H_{t-1} B
$$

where $H_{t}=\left[\begin{array}{ll}H_{i i, t} & H_{i j, t} \\ H_{j i, t} & H_{j j, t}\end{array}\right]$ represents the conditional covariance matrix of $r_{i}$ and $r_{j}$, and $\varepsilon_{t}=\left[\begin{array}{l}\varepsilon_{i, t} \\ \varepsilon_{j, t}\end{array}\right]$ is the innovation vector. $C=\left[\begin{array}{cc}C_{i i} & 0 \\ C_{i j} & C_{j j}\end{array}\right], \mathbf{A}=\left[\begin{array}{ll}a_{i i} & a_{i j} \\ a_{j i} & a_{j j}\end{array}\right]$ and $\mathbf{B}=\left[\begin{array}{ll}b_{i i} & b_{i j} \\ b_{j i} & b_{j j}\end{array}\right]$ are the parameters.

To detect the volatility spillovers between $r_{i}$ and $r_{j}$, the following hypotheses were tested according to Equation 3 and Equation 4.

$$
\begin{aligned}
& H_{0}: a_{i j}=a_{j i}=b_{i j}=b_{j i}=0 \\
& \mathrm{H}_{1}: a_{i j} \neq 0 \text { or } a_{j i} \neq 0 \text { or } b_{i j} \neq 0 \text { or } b_{j i} \neq 0,
\end{aligned}
$$

where $H_{0}$ is the null hypothesis and $H_{1}$ is the alternative hypothesis. By convention, we reject the null hypothesis at a $90 \%$ confidence level. If the null hypothesis is rejected, it means that there are spillovers between $r_{i}$ and $r_{j}$. Specifically, the direction of the spillover effect is from $r_{i}$ to $r_{j}$ when $a_{i j} \neq 0$ or $b_{i j} \neq 0$. Otherwise, the direction is from $r_{j}$ to $r_{i}$ when $a_{j i} \neq 0$ or $b_{j i} \neq 0$.

To test volatility spillovers between multiple variables, a set of bivariate BEKK-GARCH models is required. After all testing has been completed, we can identify the BEKK-GARCH-based volatility spillover networks. Let $\operatorname{Net}(V, E)$ represent the industry-specific securities index volatility spillover networks. The set $V=\left\{v_{1}, v_{2}, \cdots, v_{N}\right\}$ represents the vertices, also called nodes, of industry securities indices. Each of the nodes $v_{i}$ is characterized by a $\log$ return time series $r_{i}$. The set $E$ represents the edges of the networks. For $\forall v_{i}, v_{j} \in V$, the edges from $v_{i}$ to $v_{j}$ satisfy the indicator function $e_{i j}$, which is shown in Equation 5 :

$$
e_{i j}=\left\{\begin{array}{c}
1 \quad \text { if } i \neq j \text { and there is volatility spillover from } r_{i} \text { to } r_{j} \\
0 \text { otherwise }
\end{array}\right.
$$


We then considered the weight of $e_{i j}$. By referencing Liu et al. (2017) and Feng et al. (2018) we calculated the weight of the edges according to Equation 6 and Equation 7:

$$
\begin{aligned}
& w_{i j}=\left|a_{i j}\right|+\left|b_{i j}\right| \\
& w_{j i}=\left|a_{j i}\right|+\left|b_{j i}\right|
\end{aligned}
$$

where the weights of $e_{i j}$ and $e_{j i}$ are represented by $w_{i j}$ and $w_{j i}$, respectively. Weighted and directed BEKKGARCH-based volatility spillover networks have now been identified. The intensity of the edge $e_{i j}$ can be calculated as $s_{i j}=e_{i j} w_{i j}$.

\subsection{Node Importance Ranking Indicators \\ 3.2.1. Connectivity and Relative Influence}

The connectivity indicators consist of $O_{i}$ and $I_{i}$, which represent the total intensity of outward spillovers from $v_{i}$ and the total intensity of inward spillovers to $v_{i}$, respectively. $O_{i}$ and $I_{i}$ were calculated according to Equation 8 and Equation 9:

$$
o_{i}=\sum_{j=1_{i} \neq i}^{N} s_{i j} \quad(8) \quad I_{i}=\sum_{j=1_{j} \neq i}^{N} s_{j i}
$$

Both $O_{i}$ and $I_{i}$ are absolute indicators. The relative influence of $v_{i}$ was calculated according to Equation 10:

$$
r i_{i}=\left\{\begin{array}{c}
\frac{O_{i}-I_{i}}{O_{i}+I_{i}}, \text { otherwise } \\
0, \text { if } O_{i}+I_{i}=0
\end{array}\right.
$$

When dividing the nodes into groups, additional indicators were required to assess the importance of the groups according to Billio, Getmansky, Lo, and Pelizzon (2012). The outward spillover effect from the nodes in one group to those in other groups can be defined as "total out to other" (TOTO). Similarly, the inward spillover to one group from other groups can be defined as "total in from other" (TIFO). The TOTO and TIFO are shown in Equation 11 and Equation 12:

$$
\operatorname{TOTO}_{i}=\sum_{j=1}^{N-N_{m}} s_{i j}, v_{j} \in V \backslash V_{m} \quad(11) \quad \text { TIFO }=\sum_{j=1}^{N-N_{m}} s_{j i}, v_{j} \in V \backslash V_{m}
$$

where $v_{i}$ belongs to subset $V_{m}=\left\{v_{i}[i \in m\}\right.$, which includes $N_{m}$ nodes. Let $V_{m}, V_{n} \subset V_{\text {satisfy }} V_{m}=\left\{v_{i} \mid i \in m\right\}$

and $V_{n}=\left\{v_{j}[j \in n\}\right.$. We calculated the sector influence indicator according to Equation 13:

$$
S I_{m n}=\frac{1}{N_{m} N_{n}} \sum_{i \in m} \sum_{j \in n} s_{i j}
$$

The higher the value of $S I_{m n}$ is, the more intensive the spillover is from subset $V_{m}$ to subset $V_{n}$. 


\subsubsection{Weighted K-Shell Decomposition}

In addition to the number of neighbors, the location of a node in the network is also critical for the assessment of its importance. Kitsak et al. (2010), therefore, proposed k-shell decomposition to evaluate the locational importance of the nodes. K-shell decomposition is the method that reshapes the networks into a layered structure according to their connectivity patterns. For an unweighted network $\mathrm{N}_{0}=\operatorname{Net}\left(V_{0}, \mathrm{E}_{0}\right)$, the layer $L$ of $N_{0}$ is a subset of nodes, each of which has only one neighbor. We assigned the layer an integer label $L_{1}$ and removed it from $N_{0}$. We then obtain a new network $\mathrm{N}_{1}=\operatorname{Net}\left(V_{1}, \mathrm{E}_{1}\right)$. Similarly, we identified the layer of the network $N_{n-1}$, assigned the layer a label $L_{n}$ and removed it from the network. After repeating the step $K$ times, each of the nodes in the original network $\mathrm{N}_{0}$ can be assigned to one of the layers.

Vanilla k-shell decomposition fails to consider the intensity of connections, thus it cannot rank the nodes for weighted networks. Garas, Schweitzer, and Havlin (2012) extended vanilla k-shell decomposition to weighted kshell decomposition. The alternative measure for node degree is shown in Equation 14.

$$
w k_{i}=\left[k_{i}^{\alpha} O_{i}^{\beta}\right]^{\frac{1}{\alpha+\beta}}
$$

where $k_{i}$ represents the number of neighbors connected with $v_{i}$, and $O_{i}$ is defined in Equation 8. According to Garas et al. (2012), the parameters can be set as $\alpha=\beta=1$. Note that $w k_{i}$ is not an integer value. Therefore, we should first divide all the weights of edges in $\mathrm{N}_{0}$ by their minimum value and discretize the resulting weights by rounding to their closest integer. Then, we obtain $\mathrm{N}_{0}^{f}=\operatorname{Net}\left(V_{0}, \mathrm{E}_{0}^{z}\right)$, in which the minimum value of the weights equal to 1. Each step of the weighted k-shell decomposition consists of the following: first, normalize $\mathbb{N}_{\mathrm{n}}$ to $\mathbb{N}_{\mathrm{n}}^{\prime}$, second, identify layer $k=n+1$, and third, remove the layer from $\mathrm{N}_{\mathrm{n}}$, and obtain $\mathrm{N}_{\mathrm{n}+1}$.

\subsubsection{Betweenness Centrality}

Betweenness centrality is based on the shortest distances between nodes (Opsahl, Agneessens, \& Skvoretz, 2010). For weighted directed networks, the definition of the shortest distance from $v_{i}$ to $v_{j}$ is shown in Equation 15:

$$
d_{i j}^{\alpha}=\min _{D_{i j}}\left\{\left(s_{i d_{1}}^{-\alpha}+s_{d_{1} d_{2}}^{-\alpha}+\cdots+s_{d_{k j} j}^{-\alpha}\right), s_{i j}^{-\alpha}\right\}
$$

where $D_{i j}=\left\{v_{d_{1}} v_{d_{2}}, \cdots, v_{d_{k}}\right\}, 1 \leq k \leq N-2$ represents a set of arbitrary intermediate nodes of the spillover paths from $v_{i}$ to $v_{j}$. The set of the intermediate nodes of the shortest path can therefore be defined as $D_{i j}^{*}$. If $d_{i j}^{\alpha}=s_{i j}^{-\alpha}$, then there are no intermediate nodes in the shortest path from $v_{i}$ to $v_{j}$, and $D_{i j}^{*}=\emptyset$. For 
unweighted networks, the parameter $\alpha$ simply equals zero. For weighted networks, the value of $\alpha$ depends on the relationship between the link intensity between the nodes and their distance. In the weighted and directed spillover networks of financial markets, the higher link intensity between the nodes means a shorter distance. The value of $\alpha$ should be positive. If there are more intermediate nodes in the spillover path between two nodes, then their distance is longer. $\alpha$ is supposed to be less than 1, so with a comprehensive consideration, we take $\alpha=0.5$

We can easily define the betweenness and the closeness based on the definition of the shortest distance $d_{i j}^{\alpha}$. We call the weighted betweenness centrality of $v_{i}$.the $W B C_{i}$. The $W B C_{i}$ represents the proportion of shortest paths from $v_{j}$ to $v_{k}$, which includes $v_{i}$ as an intermediate node, it can be calculated by Equation 16 .

$$
W B C_{i}=\sum_{i \neq j \neq k} \frac{g_{j k}(i)}{g_{j k}}
$$

where $g_{j k}$ is the number of different $D_{j k}^{*}$, and $g_{j k}(i)$ is the number of $D_{j k}^{*}$ including $v_{i}$ as an intermediate node.

\subsection{Earth Mover's Distance (EMD)}

None of the indicators introduced in Section 3.2 highlights measuring the distributional change in the spillover intensity. Therefore, we introduce the EMD to consider the intensity distribution change in spillovers across different groups. The EMD is a cross-bin distance that is defined as the minimal cost that must be paid to transform one histogram into another (Rubner, Tomasi, \& Guibas, 2000). An intensity distribution of spillovers can be represented by countable clusters. Each cluster is represented by its mean and by the fraction of the distribution that belongs to that cluster. We refer to such a representation as the signature of the distribution. Then, the distributional change in spillover intensity between periods 1 and 2 can be formalized and solved as a transportation problem. We transformed the distribution of link strength in periods 1 and 2 into signatures $\delta_{1}$ and $\delta_{2}$, respectively, according to Equation 17:

$$
\left\{\begin{array}{l}
S_{1}=\left\{\left(S_{11}, p_{S_{11}}\right),\left(S_{12}, p_{S_{12}}\right), \cdots,\left(S_{1 m}, p_{S_{1 m}}\right)\right\} \\
S_{2}=\left\{\left(S_{21}, p_{S_{21}}\right),\left(S_{22}, p_{S_{22}}\right), \ldots,\left(S_{2 n}, p_{S_{2 n}}\right)\right\}
\end{array}\right.
$$

where the intensity distribution of the spillovers in periods 1 and 2 are discretized into $m$ and $n$ clusters.

$S_{1 i}$ and $S_{2 j}$ represent the means of the ith cluster in period 1 and the $j$ th cluster in period 2 , respectively. Both $S_{1 i}$ and $S_{2 j}$ are one-dimensional real values, and we defined the ground distance between the $i t h$ cluster in period 1 and the $j$ th cluster in period 2 as $\mathrm{d}_{\mathrm{ij}}=\left|S_{1 i}-S_{2 j}\right|$. The $p_{x}$ represents the weight of cluster $x$. In addition, $p_{x}$ 
naturally satisfies $\sum_{i=1}^{m} p_{S_{1 i}}=\sum_{j=1}^{n} p_{S_{2 j}}=1$. The calculation of the EMD can be transformed into the optimization of a transporting problem, which can be solved via the Hungarian method.

\section{DEMAND-ORIENTED INDUSTRY-SPECIFIC VOLATILITY SPILLOVER NETWORK} ANALYSIS

\subsection{Network before the COVID-19 Outbreak}

Table 2 reports the summary of the nodes in period 1 by group. The Kg group is a significant volatility supplier in the network. The median of $O_{i}$ and that of $T O T O_{i}$ of the nodes in the $\mathrm{Kg}$ group are 6.71 and 5.39, which are much higher than those of other groups. The indicator $\sum$ TOTO/ $\Sigma O$ measures the proportion that outward spillovers from one sector group to other groups accounts for in its total spillovers. The unclassified services group (Us) has the highest value of $\sum T O T O / \sum O$, which is $78.55 \%$. The medians of $I_{i}$ and $T I F O_{i}$ of the Ke group are 5.67 and 4.48 , respectively. Meanwhile, the value of $\sum T I F O / \sum I$ of this group is also the highest, which is $78.58 \%$ of its total $I_{i}$. The $\mathrm{Kg}$ group is also the only one with a positive median of $r i_{i}(0.09)$. Those of the other three groups are all negative values, in which the lowest value (-0.15) belongs to the $\mathrm{Cg}$ group. The median of $W B C_{\tilde{i}}$ of the $\mathrm{Kg}$ group is 39 , which is also much higher than the other group counterparts. The median of $W B C_{\tilde{i}}$ of the Us group is 16 , which is the lowest value. It means that many intensive spillover paths go through the Kg group, while few of them go through the Us group.

Table 2. Medians for indicators of the nodes by sector group in period 1 (before the COVID-

\begin{tabular}{c|c|c|c|c|c|c}
\hline Sector group & O & TOTO & I & TIFO & Ri & WBC \\
\hline $\mathrm{Ke}$ & 4.50 & 3.54 & 5.67 & 4.48 & -0.09 & 17.5 \\
\hline $\mathrm{Cg}$ & 4.54 & 2.56 & 5.21 & 3.84 & -0.15 & 21 \\
\hline $\mathrm{Kg}$ & 6.71 & 5.39 & 5.50 & 3.69 & 0.09 & 39 \\
\hline $\mathrm{Us}$ & 4.55 & 3.81 & 4.61 & 3.77 & -0.05 & 16 \\
\hline
\end{tabular}

Table 3 reports the intergroup spillovers of the network in period 1. We can find the significant asymmetry in the spillover between the $\mathrm{Kg}$ and $\mathrm{Cg}$ groups. Both the gross and net spillovers from $\mathrm{Kg}$ to $\mathrm{Cg}$ are the highest among all gross and net intergroup spillovers, which are 49.02 and 16.22. In addition, the net spillover from $\mathrm{Kg}$ to Ke is 14.8. Relatively, there is only slight asymmetry in the rest of spillovers. The net spillover from $\mathrm{Cg}$ to Ke is much weaker than that from $\mathrm{Kg}$ to $\mathrm{Cg}$. Thus, integrating the $\mathrm{Kg}$ and Ke groups as a whole sector group meeting the investment demand has a net spillover to the Cg group.

In period 1, the Kg group is a main spillover contributor from all perspectives. The outward spillovers from $\mathrm{Kg}$ to other groups account for $23.2 \%$ of total spillovers in the network. In contrast, the Cg group is the main receiver of spillovers, which receives $22.3 \%$ of the total spillovers. The Ke group also receives $20.3 \%$ of the total spillovers, which is only slightly lower than that of the Cg group. In addition, the other three groups have net spillovers to the Ke group. 
Table 3. Cross-sector group analysis of the volatility spillovers in period 1 (before the COVID-19 outbreak).

\begin{tabular}{|c|c|c|c|c|c|c|c|c|c|c|}
\hline \multirow{2}{*}{ From/to } & \multicolumn{5}{|c|}{ Intensity of spillovers } & \multicolumn{5}{|c|}{ No. of direct spillover paths } \\
\hline & Ke & $\mathrm{Cg}$ & Kg & Us & Total & Ke & $\mathrm{Cg}$ & Kg & Us & Total \\
\hline Ke & 30.16 & 36.73 & 26.05 & 21.04 & \multirow{4}{*}{537.55} & 223 & 307 & 207 & 222 & \multirow{4}{*}{4308} \\
\hline $\mathrm{Cg}$ & 40.64 & 43.24 & 32.80 & 30.79 & & 295 & 374 & 268 & 268 & \\
\hline Kg & 40.81 & 49.02 & 37.67 & 34.62 & & 284 & 372 & 247 & 245 & \\
\hline Us & 27.74 & 34.50 & 27.19 & 24.54 & & 217 & 292 & 202 & 198 & \\
\hline
\end{tabular}

\subsection{Network at the Beginning of the COVID-19 Outbreak}

Table 4 reports the summary of the nodes in period 2 by group. The median of $O_{i}$ and that of $T$ OTO $O_{i}$ of the $\mathrm{Kg}$ group are 8.81 and 6.39, respectively, which are even higher than those in period 1. The Kg group also has the highest value of $\sum$ TOTO/ $\sum O$, which is $76.21 \%$. The median of $O_{i}$ and that of TOTO $O_{i}$ of the Us group are 6.15 and 4.46, respectively, which increased the most significantly compared to those in period 1 . The median of $I_{\tilde{i}}$ and that of IFO $_{i}$ of the Ke group are the highest, which are 8.81 and 6.39 , respectively. The median of $I_{i}$ and that of TIFO $_{i}$ of the $\mathrm{Cg}$ group are 5.58 and 4.65, respectively. Moreover, the value of $\sum$ TIFO/ $\sum I$ of this group is also the highest and exceeds $80 \%$. The highest median of $r i_{i}$ is that of the $\mathrm{Kg}$ group, which is 0.2 . The lowest value is that of the $\mathrm{Cg}$ group, which is -0.31 . In period 2 , the difference in $r i_{i}$ among sector groups enlarged compared with that in period 1. The median of $W B C_{i}$ of the $\mathrm{Kg}$ group is 33, which is still the highest. However, the median of $W B C_{i}$ of the Us group is 27 , which increased rapidly. This means that the centrality of nodes in the Us group becomes much higher.

Table 4. Medians for indicators of the nodes by sector group in period 2 (at the beginning of the COVID-19 outbreak).

\begin{tabular}{c|c|c|c|c|c|c}
\hline Sector Group & O & TOTO & I & TIFO & Ri & WBC \\
\hline Ke & 5.19 & 3.96 & 6.74 & 4.71 & -0.13 & 18 \\
\hline $\mathrm{Cg}$ & 3.61 & 2.14 & 5.58 & 4.65 & -0.31 & 8 \\
\hline $\mathrm{Kg}$ & 8.81 & 6.39 & 5.58 & 3.38 & 0.20 & 33 \\
\hline $\mathrm{Us}$ & 6.15 & 4.46 & 5.48 & 4.37 & -0.06 & 27 \\
\hline
\end{tabular}

Table 5 reports the intergroup spillovers of the network in period 2. We can see that the total spillover intensity and the number of spillover paths in period 2 are significantly higher than those in period 1. This means that the outbreak of COVID-19 intensified the overall spillovers in China's stock market. The gross and net outward spillovers from $\mathrm{Kg}$ to $\mathrm{Cg}$ are 61.37 and 36.32, respectively, which account for a higher proportion of total spillovers than those in period 1. Specifically, the proportion of the gross spillover from $\mathrm{Kg}$ to $\mathrm{Cg}$ increased from $9.1 \%$ to $9.5 \%$ of the total spillovers of the network. The proportion of the net spillover increased even more rapidly from $3.0 \%$ to $5.6 \%$. In addition, the Ke and $\mathrm{Kg}$ groups, as an integral whole, still have a net spillover effect on the Cg group.

In period 2, the outward spillovers from $\mathrm{Kg}$ to other groups account for $24.0 \%$ of the total spillovers of the network. The $\mathrm{Cg}$ group received $24.3 \%$ of the total spillovers. In addition, the other three groups have net outward spillovers to the $\mathrm{Cg}$ group, including the Ke group. Therefore, $\mathrm{Kg}$ and $\mathrm{Cg}$ can be viewed as the major contributor and receiver, respectively, of the spillovers in period 2. 
Table 5. Cross-sector group analysis of the volatility spillovers in period 2 (at the beginning of the COVID-19 outbreak).

\begin{tabular}{|c|c|c|c|c|c|c|c|c|c|c|}
\hline \multirow{2}{*}{ From/to } & \multicolumn{5}{|c|}{ Intensity of spillovers } & \multicolumn{5}{|c|}{ No. of spillover paths } \\
\hline & Ke & $\mathrm{Cg}$ & $\mathrm{Kg}$ & Us & Total & Ke & $\mathrm{Cg}$ & Kg & Us & Total \\
\hline Ke & 42.48 & 46.01 & 31.08 & 36.65 & \multirow{4}{*}{646.31} & 277 & 348 & 230 & 234 & \multirow{4}{*}{4537} \\
\hline $\mathrm{Cg}$ & 36.04 & 35.98 & 25.05 & 28.79 & & 267 & 328 & 261 & 252 & \\
\hline $\mathrm{Kg}$ & 47.08 & 61.37 & 48.84 & 46.91 & & 301 & 403 & 273 & 275 & \\
\hline Us & 38.09 & 49.51 & 33.26 & 39.17 & & 214 & 313 & 222 & 245 & \\
\hline
\end{tabular}

\subsection{Network after Preliminary Containment of Covid-19}

Table 6 reports the summary of the nodes in period 3 by group. Instead of the Kg group, the Us group has the highest outward spillover effect in period 3. The median of $O_{i}$ and that of $T$ OTO $O_{i}$ of the Us group are 5.37 and 4.43.

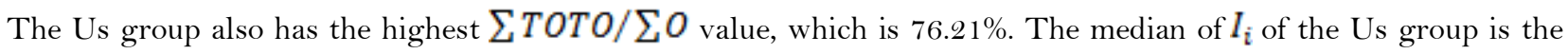
highest, which is 5.76. However, the $\sum$ TIFO/ $\sum I$ value of the Us group is not relatively high. This reveals that in period 3, the intragroup spillovers between the nodes in the Us group increased significantly. The Ke group still has the highest median of IFO $_{i}$ (4.18). Moreover, the $\sum T I F O / \sum I$ value of group Ke is $78.41 \%$. The $\mathrm{Kg}$ group has the highest median of $r i_{i}(0.05)$, which is still the only positive value. The lowest value belongs to the $\mathrm{Cg}$ group, which is -0.18. In period 3, the gap of $r i_{i}$ between different sector groups became narrower than in period 2.

The Us group, instead of the $\mathrm{Kg}$ group, became the group with the highest median of $W B C_{i}$, the value of which is 28. In addition, the median of $W B C_{\tilde{i}}$ of the $\mathrm{Kg}$ group is 27 , which is only slightly lower than that of the Us group.

Table 6. Medians for indicators of the nodes by sector group in period 3 (after COVID-19 is preliminarily contained).

\begin{tabular}{c|c|c|c|c|r|r}
\hline Sector group & O & TOTO & I & TIFO & Ri & WBC \\
\hline Ke & 4.70 & 3.76 & 5.42 & 4.18 & -0.12 & 25 \\
\hline $\mathrm{Cg}$ & 3.95 & 2.52 & 5.46 & 3.82 & -0.18 & 9 \\
\hline $\mathrm{Kg}$ & 5.19 & 4.22 & 5.58 & 4.10 & 0.05 & 27 \\
\hline $\mathrm{Us}$ & 5.37 & 4.33 & 5.76 & 3.96 & -0.01 & 28 \\
\hline
\end{tabular}

Table 7 reports the intergroup spillovers of the network in period 3. Both the total spillover intensity and the number of spillover paths in period 3 are less than those in period 2 . The most significant difference between the intergroup spillovers in period 3 and those in periods 1 and 2 is the occurrence of the net outward spillover from the Us group to the $\mathrm{Kg}$ group. The Us group, therefore, has the net outward spillovers to other three groups. In addition, the Ke and $\mathrm{Kg}$ groups, as an integral whole, still have the net spillover to the Cg group.

In period 3, the outward spillovers from the Us group account for $20.4 \%$ of the total spillovers of the network. The inward spillovers received by the $\mathrm{Cg}$ group accounted for $21.9 \%$ of the total spillovers. Therefore, the Us and $\mathrm{Cg}$ groups were the major contributor and receiver, respectively, of the spillovers in period 3. 
Table 7. Cross-sector group analysis of the volatility spillovers in period 3 (after COVID-19 is preliminarily contained).

\begin{tabular}{|c|c|c|c|c|c|c|c|c|c|c|}
\hline \multirow{2}{*}{ From/to } & \multicolumn{5}{|c|}{ Intensity of spillovers } & \multicolumn{5}{|c|}{ No. of spillover paths } \\
\hline & Ke & $\mathrm{Cg}$ & Kg & Us & Total & Ke & $\mathrm{Cg}$ & $\mathrm{Kg}$ & Us & Total \\
\hline Ke & 30.36 & 34.33 & 28.36 & 27.42 & \multirow{4}{*}{566.29} & 209 & 283 & 220 & 229 & \multirow{4}{*}{4254} \\
\hline $\mathrm{Cg}$ & 39.40 & 47.55 & 35.03 & 32.77 & & 278 & 373 & 261 & 283 & \\
\hline $\mathrm{Kg}$ & 35.40 & 41.61 & 33.25 & 32.19 & & 250 & 326 & 232 & 253 & \\
\hline Us & 32.77 & 48.30 & 34.61 & 32.95 & & 211 & 305 & 206 & 220 & \\
\hline
\end{tabular}

In conclusion, there are both stable patterns and significant changes in the demand-oriented industry-specific volatility spillover networks of China's stock market during the study period. First, viewing the Kg and Ke sector groups as an integral whole, they maintained significant net spillovers to the $\mathrm{Cg}$ group. Such spillovers were relatively stronger in period 2 than in the other two periods. Second, the $\mathrm{Kg}$ group always had a net outward spillover to the Ke group. Furthermore, the importance of the Us group increased and finally became the major contributor of the spillovers in period 3. Figure 2 depicts the simplified spillover paths of networks in different periods by sector group.

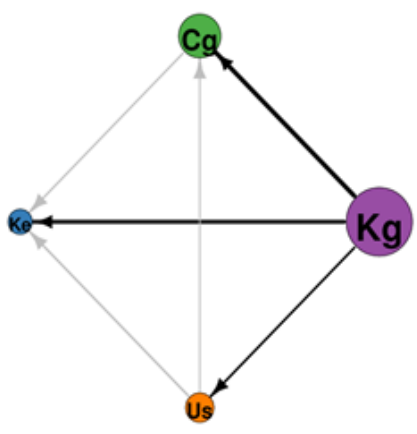

Period 1

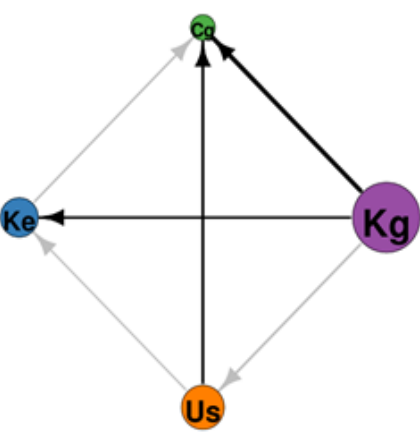

Period 2

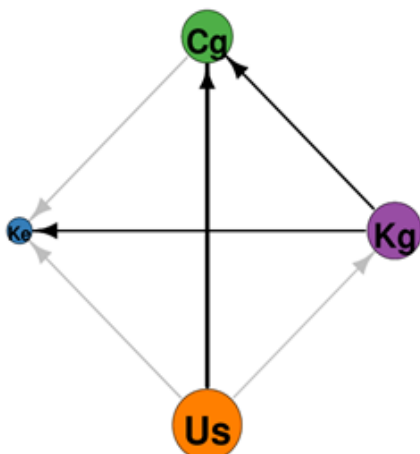

Period 3

Figure 1. Demand-oriented industry-specific volatility spillover networks in different periods (net effect by sector group).

Notes: The size of each node represents the total spillover effects from this sector group to others. The width and direction of each arrow represent the strength and direction of net spillover effect between the relevant pairs of sector groups, respectively. The black arrows in each subfigure represent the major paths in each period obtained through the maximum spanning tree method.

According to Figure 1, the spillover paths from $\mathrm{Kg}$ to $\mathrm{Cg}$ and Ke were stable in all periods. The outbreak of COVID-19 led to an increasing rise in the importance of the spillover paths from the Us group to other groups. In particular, the path from Us to $\mathrm{Cg}$ became one of the major paths of the spillover networks of China's stock market after the outbreak.

The findings of this section have inspiring economic implications. First, some studies, such as Justiniano, Primiceri, and Tambalotti (2010), proved that fluctuations in investment demand caused by exogenous factors are the main cause of fluctuations in China's economic demand. Our numerical findings further show that the structural change in volatility spillover networks of China's stock market can reflect the critical role that investment demand plays in the fluctuation of China's economic demand since the outbreak of COVID-19. On the one hand, the Kg and Ke groups, as an integral whole, are the stable spillover contributors to the $\mathrm{Cg}$ group in the networks. On the other hand, the outward spillover effect from the $\mathrm{Kg}$ and $\mathrm{Ke}$ groups to the $\mathrm{Cg}$ group rapidly rose at the beginning of the COVID-19 outbreak. After the outbreak was preliminarily contained, these spillovers significantly fell. One of the main types of damage caused by COVID-19 was the nationwide closure and idling of plants in all trades, which has undisputedly had an enormous impact on investment demand in China. The increased uncertainty of investment demand led to the fluctuation in stock prices of securities in the industry sectors, which supplies goods or services to meet the investment demand. Therefore, regarding the change in spillovers from the Ke and $\mathrm{Kg}$ sector groups to 
the $\mathrm{Cg}$ group provides empirical evidence, from the perspective of the financial market, for the economic theories proposed in literature by Greenwood, Hercowitz, and Krusell (2000).

Second, the increasingly rising importance of the Us sector group in spillover networks reveals the occurrence of supply restrictions on the service industry caused by the implementation of NPIs. To contain COVID-19, the Chinese government implemented immediate NPIs nationwide. The majority of businesses in the service sector were forced to shut down, and a large percentage of transportation services in China had to idle, despite the enormous freight and passenger traffic demands. The uncertainty of COVID-19 transformed into the uncertainty of the operational environment of the companies in the service sector and, consequently, their asset prices. According to Xu and Zhang (2020), service supply restrictions will lead to an imbalance between supply and demand and will negatively affect economic growth. As a result, companies in the service sector contribute more volatility spillovers to those in other sectors. When overseas market demand is strong, a country is still able to achieve high economic growth under the condition of service supply restrictions. However, once the overseas market demand becomes insufficient, service supply restrictions will seriously damage the economy. As introduced in section 2.1, COVID-19 began to spread outside China in period 3. As a global pandemic, COVID-19 will surely lead to insufficient overseas demand for Chinese products. As a result, the importance of the Us group in the networks in period 3 is even higher than in period 2. In addition, according to Herrendorf and Fang (2019), to compare the period in which developed countries were at a similar stage of development as China is currently, there is severe supply restriction on most service industries currently in China. Service supply restriction is an overall problem rather than a structural problem in the Chinese economy. The outbreak of COVID-19 was only an exogenous shock that intensified the problem. Therefore, we believe that our findings are still representative, although not all service industry sectors are classified as members in the Us group according to the SWS standard.

\section{FURTHER DISCUSSIONS}

We further discussed the demand-oriented industry-specific volatility spillover networks of China's stock market from three aspects. First, we calculated the earth mover's distance (EMD) of the distributions of the spillover intensity of both inter- and intra-sector groups in different periods. Second, defining the major spillover paths as those with the top $20 \%$ highest intensity among a set of paths, we discussed the major spillover paths between different sector groups and their changes in different periods. Third, from various perspectives, we selected the systemically important nodes of the networks in different periods.

\subsection{EMDs Between Spillover Intensity Distributions in Different Periods}

Figure 2 depicts the intensity distributions of the spillovers between sector groups. Intensity distributions of the spillovers, both intergroup and intragroup, are right-skewed. Few spillover paths have high intensity. Most of the subfigures show that the intensity distributions of spillovers in period 1 are similar to their counterparts in period 3. The intensity distributions in period 2 , in contrast, are significantly different from those in periods 1 and 3. This reveals that in period 2, the industry-specific volatility spillover network of China's stock market has significant structural changes. As an exception, the intensity distribution of the intragroup spillover paths of the Us group, and of intergroup spillover paths between the Us and $\mathrm{Cg}$ groups in period 2, are more similar to their counterparts in period 3, rather than to those in period 1. This exception is also consistent with the findings in section 4 and proves that COVID-19 had a more long-lasting impact on the service sector than on other sectors. 


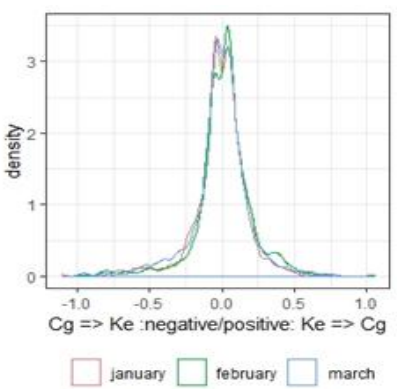

(a) $\mathrm{Ke} \& \mathrm{Cg}$

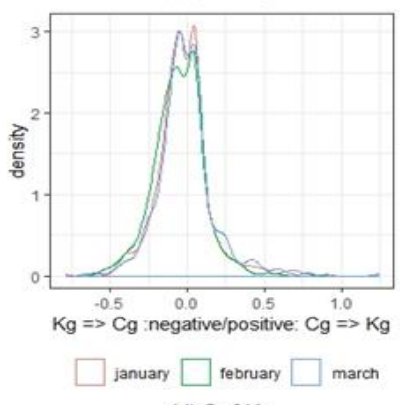

(d) $\mathrm{Cg} \& \mathrm{Kg}$

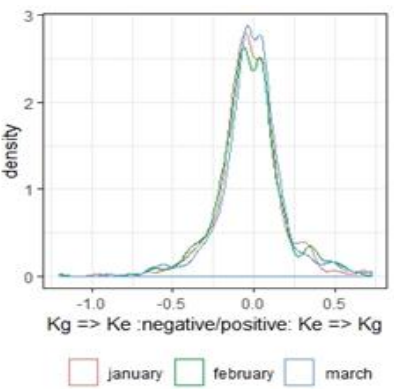

(b) Ke\&Kg

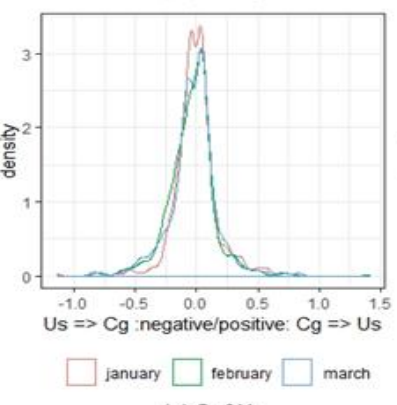

(e) Cg\&Us

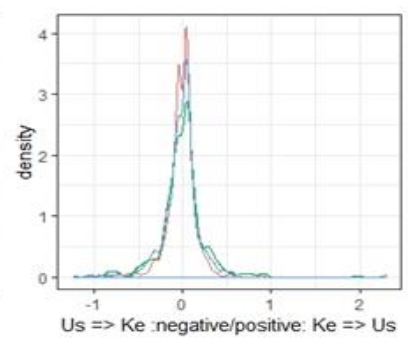

$\square$ january $\square$ tebruary $\square$ march (c) Ke\&Us

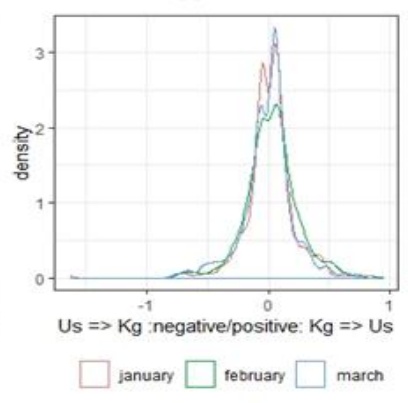

(f) Kg\&Us

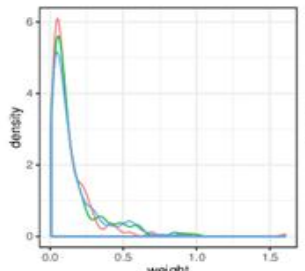

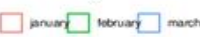

(g) intra-group Ke

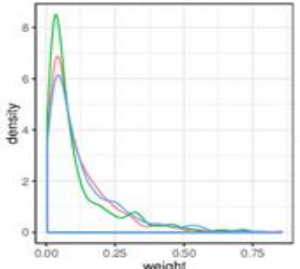

$\square$ iment $\square$ monam $\square$ mact

(h) intra-group $\mathrm{Cg}$

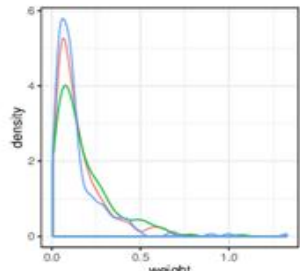

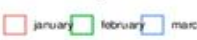

(i) intra-group Kg

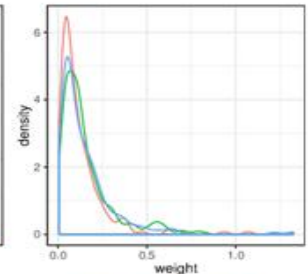

$\square$ inum $\square$ unner $\square$ masch

(j) intra-group Us

Figure 2. Empirical probability density functions of spillover intensity in different periods

Notes: From subfigure (a) to subfigure (f), to distinguish the spillover paths in one direction to another, we processed the data further following the rule called "sector group B=>sector group A: negative/positive: sector group A=>sector group B". Following this rule, when drawing the PDFs, we took the original value of the intensity of the spillover paths from sector group A to sector group B. Otherwise, we took the opposite number of the intensity of the spillover paths from sector group B to sector group A.

Table 8 shows the EMDs between spillover intensity distributions in different periods. Between periods 1 and 2, most of the high EMDs were connected with the distribution changes in spillovers between the Us group and other groups. Specifically, the EMD of the change in the intensity distribution of spillovers from Ke to Us is $6.34 \%$, and those from the Us group to the Ke and $\mathrm{Cg}$ groups are $5.11 \%$ and $4.38 \%$, respectively. Between periods 2 and 3 , most of the high EMDs were connected with the distribution changes in spillovers between the Kg group and other groups. Specifically, according to the EMD, the intensity distribution of the intragroup spillovers of the Kg group changed by $4.43 \%$. The EMD of the change in the intensity distribution of spillovers from $\mathrm{Kg}$ to Us and those from $\mathrm{Cg}$ to $\mathrm{Kg}$ are $4.31 \%$ and $3.71 \%$, respectively.

Table 8. EMDs between the intensity distributions of spillovers in different periods (\%).

\begin{tabular}{c|c|c|c|c|c|c|c|c}
\hline \multirow{2}{*}{ From $\backslash$ to } & \multicolumn{4}{|c|}{ Period 1 vs. Period 2 } & \multicolumn{4}{c}{ Period 2 vs. Period 3 } \\
\cline { 2 - 9 } & Ke & Cg & Kg & Us & Ke & Cg & Kg & Us \\
\hline $\mathrm{Ke}$ & 2.25 & 1.24 & 1.21 & 6.34 & 0.95 & 1.17 & 0.92 & 4.05 \\
\hline $\mathrm{Cg}$ & 1.09 & 1.39 & 2.43 & 1.37 & 1.56 & 1.70 & 3.71 & 1.01 \\
\hline $\mathrm{Kg}$ & 1.47 & 2.08 & 2.73 & 3.00 & 2.05 & 2.41 & 4.43 & 4.31 \\
\hline $\mathrm{Us}$ & 5.11 & 4.38 & 2.37 & 3.70 & 2.53 & 1.39 & 1.90 & 1.40 \\
\hline
\end{tabular}

The analysis in this section is a meaningful supplement for the analysis based on the sector influence indicator in section 4. From period 1 to period 2, the Us group is the sector group of which the spillover effect strength distribution had the most significant change. It revealed that, at the beginning of the outbreak of COVID-19, the 
nationwide implementation of NPIs is reflected immediately in the distributional characteristics of the spillover networks of China's stock market. The significant distributional change in the spillover strength concerning the Kg group from period 2 to period 3 also shows that the risk for investment demand destruction has been controlled to some extent. This is mainly due to the successful containment of COVID-19 and the resumption of work that is strongly supported by both the central and local governments of China. This means that the influence of the pandemic on the investment demand fell rapidly after the pandemic was contained in China, while the influence on service sectors was long-lasting.

\subsection{Systematically Important Nodes in the Spillover Network}

We selected the systematically important nodes in the volatility spillover networks in different periods from various perspectives.
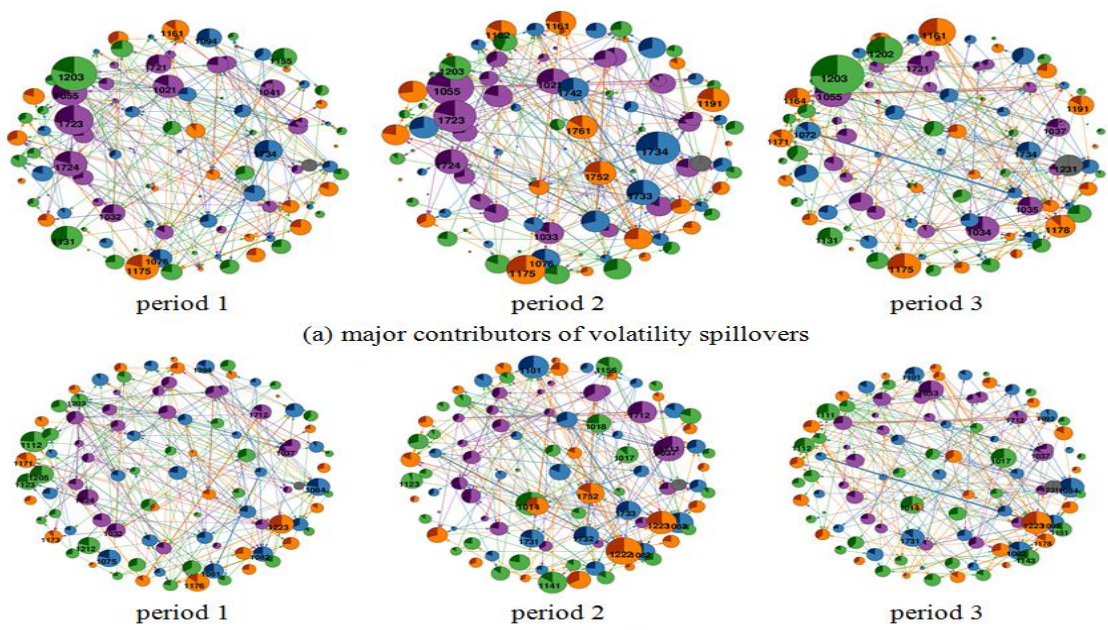

(b) major receivers of volatility spillovers

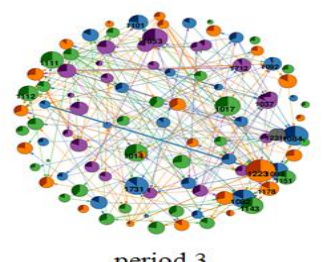

period 3

Figure 3. Major spillover effect contributors and receivers in different periods (classified by sector group).

Notes: 1. The node size of $v_{i}$ is positively correlated to $O_{i}$ (in subfigure (a)) or to $I_{i}$ (in subfigure (b)). 2. The blue, green, purple and oranges nodes represent vertices of industry indices belonging to the $\mathrm{Ke}, \mathrm{Cg}, \mathrm{Kg}$ and Us sector groups, respectively. The conglomerates industry securities index (801231) is marked as a grey node. 3. The nodes are shown as pie charts. The proportion of the part with a lighter color in the pie chart accounts for $v_{i}$ equals $T O T O_{i} / O O_{i}$ in subfigure (a))

or $T F O_{i} / I_{i}$ (in subfigure (b)). 4. The widths of edges are positively correlated with their intensity. The colors of edges are consistent with the color of nodes where they are effluent. 5 . Only edges with the top $5 \%$ highest intensity of volatility spillovers are shown in each subfigure. 6 . The industry securities index names corresponding with the 4-digit codes can be found in the appendix.

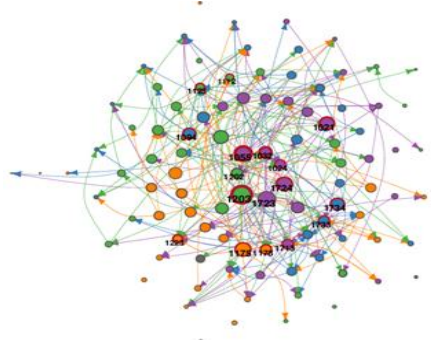

(a) period 1

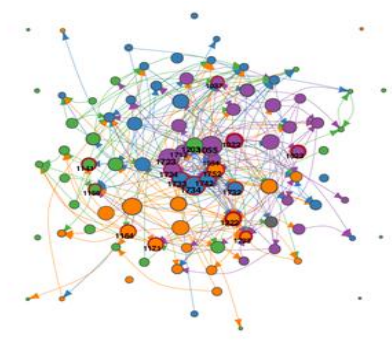

(b) period 2

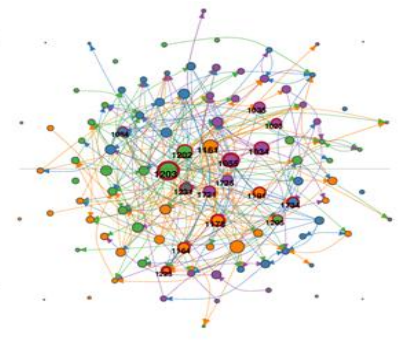

(c) period 3

Figure 4. The centrality and k-shell decomposition structure of the nodes in different periods.

Notes: 1 . The node size of $v_{i}$ is positively correlated to $O_{i}$. 2 . The blue, green, purple and oranges nodes represent vertices of industry indices in the Ke, Cg, Kg and Us groups, respectively. The conglomerates industry securities index (801231) is marked as a grey node. 3. The locations of the nodes depend on their k-shell level. 4. The nodes with red rings represent industry indices with the top 15 highest $W B C$ in the networks. 5 . The industry index names corresponding with the 4-digit codes can be found in the appendix.

According to Figure 3 (a), nodes in the commerce and trading sector (1202 and 1203), the construction sector (1721, 1723 and 1724), the utility sector (1161) and the transportation services sector (1175 and 1178) were the 
main contributors of the spillovers in all periods. Compared to period 1, a larger number of nodes in the Ke and Us groups were the main spillover contributors of the network in period 2. Compared to period 2, a larger number of nodes in the $\mathrm{Cg}$ and Us groups were the main spillover contributors of the network in period 3. According to Figure 3 (b), a list of nodes in the $\mathrm{Cg}$ group $(1014,1017,1111,1112,1212,1123,1141,1143$ and 1156) and in the Us group $(1171,1176,1123,1223$ and 1752) were the main spillover receivers of the network during the whole study period. After period 2, a larger number of nodes in the $\operatorname{Kg}(1712,1037$ and 1053) and Ke (1731, 1732, 1733, 1101 and 1084) groups were identified as the main spillover contributors of the network.

According to Figure 4, compared to the network in period 1, in period 2, a larger number of nodes in the Kg and Ke groups had a relatively higher betweenness centrality and k-shell level. However, in the network in period 3, a larger number of nodes in the Us group became the center of the networks. In conclusion, the analysis in section 5 further validates the main result in section 4. The spillovers from the $\mathrm{Kg}$ and Ke sector groups, as an integral whole, rose in period 2 and fell in period 3; the change in the spillovers from the $\mathrm{Cg}$ group is in contrast. Regarding the spillovers from sectors meeting the consumption demand of other sectors in China's stock market, our findings are consistent with those in the literature of Yang, Chen, and Zhang (2020) (in Chinese). However, we further illustrated how spillover networks of China's stock market reflected the relative rise and fall of the uncertainty of investment demand and consumption demand in China during the spread of COVID-19. Yang et al. (2020) also proposed that the service industry, which has suffered due to the pandemic, is a potential threat to economic recovery in China. In addition, Huang et al. (2020) found that more difficulties would be faced by industry sectors relying on transportation services during economic recovery. Based on the spillover networks of the stock market, our findings provide evidence for these studies.

\section{CONCLUSIONS}

According to our empirical analysis, first, the Ke and $\mathrm{Kg}$ sector groups, as a whole, had stable net spillovers to the $\mathrm{Cg}$ sector group in all of three different periods during the breakout of COVID-19. Second, the net spillovers from the $\mathrm{Ke}$ and $\mathrm{Kg}$ groups to the $\mathrm{Cg}$ group rose in period 2 but fell in period 3. Third, as of period 2, the importance of the Us sector group became increasingly higher. The Us group finally played the main contributor to the spillover network of China's stock market in period 3. We conducted further discussions from various perspectives, and all discussions validated our main result. We emphasize the need to discuss the demand change in a country. Our findings also have meaningful insights regarding economic recovery in the context of containing the spread of COVID-19. The investment demand in China suffered more than the consumption demand from the exogenous shock of COVID-19 at the beginning of the outbreak. However, when the pandemic was contained, the risk in investment demand in China was also controlled to some extent. The increasingly critical role that the Us sector group began to play revealed that the supply restriction in services is still a long-lasting threat to the next stage of Chinese economic recovery, especially under the condition that foreign demand is destroyed by COVID-19. We believe that NPIs are necessary for all countries and regions suffering from COVID-19. Thus, being aware of the overall influence of the service sector is critical for investors and policymakers globally.

Funding: This work was supported by the National Natural Science Foundation of China [71103179].

Competing Interests: The authors declare that they have no competing interests.

Acknowledgement: The authors would like to thank the editor and anonymous referees for their valuable comments.

\section{REFERENCES}

Acemoglu, D., \& Guerrieri, V. (2008). Capital deepening and nonbalanced economic growth. Journal of political Economy, 116(3), 467-498. Available at: https://doi.org/10.1086/589523. 
Billio, M., Getmansky, M., Lo, A. W., \& Pelizzon, L. (2012). Econometric measures of connectedness and systemic risk in the finance and insurance sectors. Journal of Financial Economics, 104(3), 535-559. Available at: https://doi.org/10.1016/j.jfineco.2011.12.010.

Campbell, J. Y., Lettau, M., Malkiel, B. G., \& Xu, Y. (2001). Have individual stocks become more volatile? An empirical exploration of idiosyncratic risk. The Journal of Finance, 56(1), 1-43. Available at: https://doi.org/10.1111/00221082.00318 .

Diebold, F. X., \& Yilmaz, K. (2012). Better to give than to receive: Predictive directional measurement of volatility spillovers. International Journal of Forecasting, 28(1), 57-66. Available at: https://doi.org/10.1016/j.ijforecast.201 1.02.006.

Engle, R. F., \& Kroner, K. F. (1995). Multivariate simultaneous generalized ARCH. Econometric Theory, 11(1), 122-150.

Ewing, B. T., Forbes, S. M., \& Payne, J. E. (2003). The effects of macroeconomic shocks on sector-specific returns. Applied Economics, 35(2), 201-207.

Feng, S., Huang, S., Qi, Y., Liu, X., Sun, Q., \& Wen, S. (2018). Network features of sector indexes spillover effects in China: A multi-scale view. Physica A: Statistical Mechanics and its Applications, 496, 461-473. Available at: https://doi.org/10.1016/j.physa.2017.12.091.

Garas, A., Schweitzer, F., \& Havlin, S. (2012). A k-shell decomposition method for weighted networks. New Journal of Physics, 14(8), 083030. Available at: https://doi.org/10.1088/1367-2630/14/8/083030.

Gonzalez-Navarro, M., \& Quintana-Domeque, C. (2016). Paving streets for the poor: Experimental analysis of infrastructure effects. Review of Economics and Statistics, 98(2), 254-267. Available at: https://doi.org/10.1162/rest_a_00553.

Greenwood, J., Hercowitz, Z., \& Krusell, P. (2000). The role of investment-specific technological change in the business cycle. European Economic Review, 44(1), 91-115. Available at: https://doi.org/10.1016/s0014-2921(98)00058-0.

Gupta, K., \& Chatterjee, N. (2020). Examining lead-lag relationships in-depth, with focus on FX market as Covid-19 crises unfolds. arXiv preprint arXiv: 2004.10560v2.

Herrendorf, B., \& Fang, L. (2019). High-skilled services and development in China (pp. 1-35). 2019 RBF Working Paper. Federal Reserve Bank of Atlanta: Atlanta,USA.

Huang, J., Wang, H., Xiong, H., Fan, M., Zhuo, A., Li, Y., \& Dou, D. (2020). Quantifying the economic impact of COVID-19 in mainland China using human mobility data. arXiv preprint arXiv: 2005.03010

Jiang, Y., Jiang, C., Nie, H., \& Mo, B. (2019). The time-varying linkages between global oil market and China's commodity sectors: Evidence from DCC-GJR-GARCH analyses. Energy, 166, 577-586. Available at: https://doi.org/10.1016/j.energy.2018.10.116.

Justiniano, A., Primiceri, G. E., \& Tambalotti, A. (2010). Investment shocks and business cycles. Journal of Monetary Economics, $57(2), 132-145$.

Kang, S. H., Cheong, C., \& Yoon, S.-M. (2013). Intraday volatility spillovers between spot and futures indices: Evidence from the Korean stock market. Physica A: Statistical Mechanics and its Applications, 392(8), 1795-1802. Available at: https://doi.org/10.1016/j.physa.2013.01.017.

Kitsak, M., Gallos, L. K., Havlin, S., Liljeros, F., Muchnik, L., Stanley, H. E., \& Makse, H. A. (2010). Identification of influential spreaders in complex networks. Nature Physics, 6(11), 888-893.

Lai, S., Ruktanonchai, N. W., Zhou, L., Prosper, O., Luo, W., Floyd, J. R., . . Tatem, A. J. (2020). Effect of non-pharmaceutical interventions to contain COVID-19 in China. Nature, 585(7825), 410-413. Available at: https://doi.org/10.1038/s41586-020-2293-x.

Lewis, A. L. (2020). US equity risk premiums during the COVID-19 pandemic. arXiv preprint arXiv: 2004.13871.

Lin, B., Wesseh Jr, P. K., \& Appiah, M. O. (2014). Oil price fluctuation, volatility spillover and the Ghanaian equity market: Implication for portfolio management and hedging effectiveness. Energy Economics, 42, 172-182. Available at: https://doi.org/10.1016/j.eneco.2013.12.017. 
Liu, X., An, H., Li, H., Chen, Z., Feng, S., \& Wen, S. (2017). Features of spillover networks in international financial mark ets: Evidence from the G20 countries. Physica A: Statistical Mechanics and its Applications, 479, 265-278. Available at: https://doi.org/10.1016/j.physa.2017.03.016.

Mateus, C., Chinthalapati, R., \& Mateus, I. B. (2017). Intraday industry-specific spillover effect in European equity markets. The Quarterly Review of Economics and Finance, 63, 278-298. Available at: https://doi.org/10.1016/j.qref.2016.04.011.

Opsahl, T., Agneessens, F., \& Skvoretz, J. (2010). Node centrality in weighted networks: Generalizing degree and shortest paths. Social Networks, 32(3), 245-251. Available at: https://doi.org/10.1016/j.socnet.2010.03.006.

Procacci, P. F., Phelan, C. E., \& Aste, T. (2020). Market structure dynamics during COVID-19 outbreak. arXiv preprint arXiv:2003.10922.

Rubner, Y., Tomasi, C., \& Guibas, L. J. (2000). The earth mover's distance as a metric for image retrieval. International Journal of Computer Vision, 4O(2), 99-121.

Singh, P., Kumar, B., \& Pandey, A. (2010). Price and volatility spillovers across North American, European and Asian stock markets. International Review of Financial Analysis, 19(1), 55-64. Available at: https://doi.org/10.1016/j.irfa.2009.11.001.

Singh, V. K., Nishant, S., \& Kumar, P. (2018). Dynamic and directional network connectedness of crude oil and currencies: Evidence from implied volatility. Energy Economics, 76, 48-63. Available at: https://doi.org/10.1016/j.eneco.2018.09.018.

Wang, Z. (2010). Dynamics and causality in industry-specific volatility. Journal of Banking \& Finance, 34(7), 1688-1699.

Xu, C., \& Zhang, B. (2020). The expansion of domestic demand during the transition of the economic structure: A perspective based on supply restraints in the service sector. Social Sciences in China, 2020(1), 64-83.

Yang, Z., Chen, Y., \& Zhang, P. (2020). Macroeconomic shock, financial risk transmission and governance response to major public emergencies. Management World, 36(5), 13-35.

Yarovaya, L., Brzeszczyński, J., \& Lau, C. K. M. (2016). Intra-and inter-regional return and volatility spillovers across emerging and developed markets: Evidence from stock indices and stock index futures. International Review of Financial Analysis, 43, 96-1 14. Available at: https://doi.org/10.1016/j.irfa.2015.09.004.

Yin, K., Liu, Z., \& Jin, X. (2020). Interindustry volatility spillover effects in China’s stock market. Physica A: Statistical Mechanics and its Applications, 539, 1-14. Available at: https://doi.org/10.1016/j.physa.2019.122936.

Appendix-A. SWS Industry securities index names corresponding with their codes.

\begin{tabular}{l|l|l|l}
\hline Codes & \multicolumn{1}{|c|}{ Index names } & Codes & \multicolumn{1}{c}{ Index names } \\
\hline 801011 & Forestry & 801155 & Chinese medicine \\
\hline 801012 & Agricultural Products & 801156 & Health Care Service \\
\hline 801013 & Agricultural Conglomerates & 801161 & electric Utilities \\
\hline 801014 & Feed Processing & 801162 & Environmental Facilities \& Service \\
\hline 801015 & Fishery & 801163 & Gas Utilities \\
\hline 801016 & Farming & 801164 & Water Utilities \\
\hline 801017 & Husbandry & 801171 & Marine Ports \& Service \\
\hline 801018 & Animal Health & 801172 & public transit \\
\hline 801021 & Coal Mining & 801173 & Airlines \\
\hline 801022 & other Mining & 801174 & Airport service \\
\hline 801023 & Oil \& Gas Drilling & 801175 & Highways \\
\hline 801024 & Mining Equipment \& Services & 801176 & Marine \\
\hline 801032 & chemical fiber & 801177 & Railroads \\
\hline 801033 & Chemical materials & 801178 & Trucking \\
\hline 801034 & chemical products & 801181 & Real Estate Management \& Development \\
\hline 801035 & Petrochemical Industry & 801182 & Park Exploitation \\
\hline 801036 & Plastic & 801191 & Diversified Financial Service \\
\hline 801037 & Rubber & 801192 & Banks \\
\hline 801041 & Steel & 801193 & Capital Markets \\
\hline 801051 & Metal New materials & 801194 & Insurance \\
\hline 801053 & Gold & 801202 & Trading \\
\hline
\end{tabular}




\begin{tabular}{|c|c|c|c|}
\hline 801054 & Precious Metals \& Minerals & 801203 & retailing \\
\hline 801055 & Industrial Metal & 801204 & Specialty Retail \\
\hline 801072 & General Industrial Machinery & 801205 & Commercial Property Service \\
\hline 801073 & Instrument \& Apparatus & 801211 & Catering \\
\hline 801074 & Special Equipment & 801212 & Attractions \\
\hline 801075 & Metal Products & 801213 & Hotel \\
\hline 801076 & Transporting Facilities & 801214 & Leisure Conglomerates \\
\hline 801081 & Semi-conductor & 801222 & Software \\
\hline 801082 & Other Electronic Products & 801223 & IT Services \\
\hline 801083 & Electronical Part \& Component & 801231 & Conglomerates \\
\hline 801084 & Optical \& Opto-electronic Products & 801711 & Cement \\
\hline 801085 & Electronical Manufacturing & 801712 & Glass Products \\
\hline 801092 & Automobile Services & 801713 & Other Construction Materials \\
\hline 801093 & Auto Parts \& Equipment & 801721 & Homebuilding \\
\hline 801094 & Automobile Manufacturers & 801722 & Decoration \\
\hline 801101 & Computers \& Peripherals & 801723 & Infrastructures \\
\hline 801102 & Communications Equipment & 801724 & Specialty Engineering \\
\hline 801111 & Household Appliances & 801725 & Landscape engineering \\
\hline 801112 & Audiovisuals & 801731 & electrical machinery \\
\hline 801123 & Beverage & 801732 & Electric Automation Equipment \\
\hline 801124 & Food Products & 801733 & power supply equipment \\
\hline 801131 & Textiles & 801734 & High-Low-voltage Switch Equipment \\
\hline 801132 & Apparel & 801741 & Aerospace Equipment \\
\hline 801141 & Packaging \& Printing & 801742 & Aviation Equipment \\
\hline 801142 & Household Products & 801743 & Defense Equipment \\
\hline 801143 & Paper Products & 801744 & Shipbuilding \\
\hline 801151 & Chemical pharmacy & 801751 & Advertising \& Broadcasting \\
\hline 801152 & Biotechnology & 801752 & Internet Media \\
\hline 801153 & Health Care Equipment & 801761 & Culture Media \\
\hline 801154 & Health Care Distributors & 801881 & Other Transporting Equipment \\
\hline
\end{tabular}

Appendix-B. Summary of minute-per-minute returns of the SWS securities industry indices

\begin{tabular}{|c|c|c|c|c|c|c|c|}
\hline Index & Mean(\%o) & SD (\%) & Skew & Kurt & JB test & AR 1 & ADF \\
\hline 801011 & -0.903 & 16.065 & 0.746 & 12.393 & $13395^{* * * *}$ & $-0.312^{* * *}$ & $-15.291^{* * * *}$ \\
\hline 801012 & -0.681 & 5.323 & -0.205 & 6.578 & $1921 * * *$ & $-0.167 * * *$ & $-14.535 * * *$ \\
\hline 801013 & -0.81 & 16.37 & 0.212 & 8.831 & $5061^{* * * *}$ & $-0.245^{* * *} *$ & $-16.544^{*} * * *$ \\
\hline 801014 & -1.978 & 11.613 & 1.438 & 39.187 & $195139 * * *$ & $-0.027^{* * *}$ & $-15.595^{* * * *}$ \\
\hline 801015 & -0.343 & 7.478 & -0.501 & 8.214 & $4175^{* * * *}$ & $-0.292^{* * *}$ & $-14.733^{* * * *}$ \\
\hline 801016 & -0.169 & 7.627 & 7.071 & 241.454 & $8449653^{* * * *}$ & $0.011^{* * * *}$ & -15.491 **** \\
\hline 801017 & -2.167 & 12.145 & 1.729 & 44.891 & $261638^{* * * *}$ & $-0.048^{* * *}$ & $-14.903^{* * *} *$ \\
\hline 801018 & -1.939 & 9.717 & -0.05 & 12.299 & $12805^{* * * *}$ & $-0.115^{* * * *}$ & $-15.709^{* * * *}$ \\
\hline 801021 & -0.169 & 5.56 & -0.977 & 37.747 & $179355^{* * * *}$ & $0.003^{* * *} *$ & $-14.786^{* * * *}$ \\
\hline 801022 & 1.28 & 11.014 & -0.096 & 5.133 & $679^{* * * *}$ & $-0.344^{* * *}$ & $-16.618^{* * * *}$ \\
\hline 801023 & 1.131 & 11.162 & 0.001 & 3.123 & 2 & $-0.452^{* * * *}$ & $-17.112^{* * * *}$ \\
\hline 801024 & 1.362 & 7.237 & 0.04 & 8.987 & $5308 * * *$ & $-0.142^{* * *}$ & $-13.563^{* * * *}$ \\
\hline 801032 & 0.436 & 5.511 & 0.157 & 9.999 & $7268^{* * * *}$ & $-0.066^{* * * *}$ & $-14.094^{* * * *}$ \\
\hline 801033 & -0.763 & 5.942 & -0.425 & 10.867 & $9271^{* * *}$ & $-0.136^{* * * *}$ & $-14.543^{* * * *}$ \\
\hline 801034 & -0.034 & 4.086 & -2.999 & 111.755 & $1756809 * * *$ & $0.155^{* * * *}$ & $-14.632^{*} * *$ \\
\hline 801035 & 0.543 & 8.122 & -0.022 & 3.004 & $\mathrm{O}$ & $-0.433^{* * *} *$ & $-15.593^{* * * *}$ \\
\hline 801036 & 0.146 & 6.713 & 3.799 & 114.012 & $1833495^{* * * *}$ & $-0.053^{* * * *}$ & $-15.153^{* * * *}$ \\
\hline 801037 & 0.301 & 5.605 & -0.742 & 15.213 & $22414^{* * * *}$ & $-0.11^{* * *}$ & $-14.207^{*} * *$ \\
\hline 801041 & 0.951 & 9.368 & 0.377 & 24.26 & $67013^{* * *}$ & $-0.201^{* * *}$ & $-14.351^{* * * *}$ \\
\hline 801051 & -0.608 & 5.895 & -1.513 & 29.834 & $107985^{* * * *}$ & $0.054^{* * * *}$ & $-14.748^{* * * *}$ \\
\hline
\end{tabular}


Asian Economic and Financial Review, 2020, 10(11): 1321-1341

\begin{tabular}{|c|c|c|c|c|c|c|c|}
\hline 801053 & 1.742 & 11.145 & -0.355 & 70.667 & $678131^{* * * *}$ & $-0.153^{* * *}$ & $-15.589^{* * *}$ \\
\hline 801054 & 2.997 & 7.955 & 2.589 & 40.927 & $216983^{* * *}$ & $0.062^{* * *}$ & $-15.215^{* * *}$ \\
\hline 801055 & -0.042 & 5.526 & -0.366 & 7.556 & $3154^{* * * *}$ & $-0.233^{* * *}$ & $-13.098^{* * *} *$ \\
\hline 801072 & -0.799 & 4.243 & -1.937 & 76.396 & $799947 * * *$ & $0.084^{* * * *}$ & $-14.131^{* * *}$ \\
\hline 801073 & 3.452 & 6.1 & 1.167 & 25.485 & 75674 **** & $0.018^{* * *}$ & $-15.159^{* * * *}$ \\
\hline 801074 & -1.047 & 4.677 & -2.233 & 58.968 & $466814^{* * * *}$ & $0.06^{* * *}$ & $-14.793^{* * *}$ \\
\hline 801075 & 0.098 & 5.48 & -0.329 & 8.875 & $5175^{* * * *}$ & $-0.141^{* * *}$ & $-13.245^{* * *}$ \\
\hline 801076 & -0.068 & 7.743 & 0.124 & 6.562 & $1888 * * *$ & $-0.332 * * *$ & $-15.222^{*} * *$ \\
\hline 801081 & 0.45 & 10.877 & -0.902 & 26.515 & $82365^{* * * *}$ & $0.105^{* * *}$ & $-13.42^{* * *}$ \\
\hline 801082 & 0.194 & 7.866 & 0.627 & 11.823 & $11760^{* * * *}$ & $0.077^{* * *}$ & $-14.136^{* * * *}$ \\
\hline 801083 & -1.317 & 9.022 & -1.62 & 33.36 & $138049^{* * * *}$ & $0.068 * * *$ & $-13.503 * * *$ \\
\hline 801084 & -0.144 & 8.405 & -1.465 & 30.54 & $113585^{* * * *}$ & $\mathrm{O}^{*}$ & $-14.966^{* * *}$ \\
\hline 801085 & 0.205 & 9.623 & -0.513 & 24.526 & $68771^{* * * *}$ & $0.081^{* * *}$ & $-14.303^{* * *}$ \\
\hline 801092 & 0.746 & 12.032 & -0.273 & 6.601 & $1964 * * *$ & $-0.359 * * *$ & $-16.821^{* * * *}$ \\
\hline 801093 & 0.464 & 5.12 & -1.222 & 75.057 & $769773^{* * *}$ & $0.053^{* * *} *$ & $-15.378^{* * * *}$ \\
\hline 801094 & -0.855 & 5.687 & -0.783 & 28.128 & $93863^{* * *}$ & $-0.021^{* * *}$ & $-16.051^{* * *}$ \\
\hline 801101 & -1.415 & 7.657 & -2.453 & 55.807 & $416502^{* * *}$ & $0.1^{* * *}$ & $-14.612^{* * *} *$ \\
\hline 801102 & -1.525 & 6.582 & -3.256 & 105.064 & $1548860^{* * * *}$ & $0.165^{* * *}$ & $-14.506^{* * *}$ \\
\hline 801111 & -1.699 & 7.908 & -4.988 & 116.867 & $1934734^{* * * *}$ & $0.082^{* * * *}$ & $-13.435^{* * * *}$ \\
\hline 801112 & 0.67 & 8.655 & -0.004 & 6.449 & $1762^{* * *}$ & $-0.261^{* * *}$ & $-13.704^{* * *}$ \\
\hline 801123 & 0.02 & 5.659 & 0.076 & 14.317 & $1897 \mathrm{O}^{* * * *}$ & $0.101^{* * *}$ & $-14.104^{* * *} *$ \\
\hline 801124 & -0.563 & 6.134 & -0.148 & 17.297 & $30282^{* * *}$ & $-0.025^{* * *}$ & $-14.013^{* * *}$ \\
\hline 801131 & -0.056 & 4.318 & -0.34 & 19.892 & $42321^{* * *}$ & $-0.108^{* * *}$ & $-13.335^{* * * *}$ \\
\hline 801132 & -1.593 & 5.244 & -4.632 & 115.477 & $1886105^{* * *}$ & $-0.049^{* * *}$ & $-14.272^{* * *}$ \\
\hline 801141 & -0.478 & 5.487 & -0.3 & 9.228 & $5797 * * *$ & $-0.002^{* * *}$ & $-14.648^{* * *} *$ \\
\hline 801142 & -0.532 & 4.744 & -1.367 & 45.758 & $271836^{* * *}$ & $0.025^{* * *}$ & $-14.31^{* * *}$ \\
\hline 801143 & -0.433 & 6.842 & -0.82 & 10.068 & $7796^{* * * *}$ & $-0.112^{* * *}$ & $-15.213^{* * *}$ \\
\hline 801151 & 0.74 & 5.486 & 0.174 & 45.784 & $271083^{* * *}$ & $0.119^{* * * *}$ & $-15.87^{* * *}$ \\
\hline 801152 & -1.356 & 6.436 & -1.093 & 25.637 & $76590^{* * * *}$ & $0.161^{* * *}$ & $-12.885^{* * * *}$ \\
\hline 801153 & -1.334 & 6.454 & -1.359 & 26.376 & $82010^{* * *}$ & $0.16^{* * *}$ & $-12.518^{* * *}$ \\
\hline 801154 & -1.427 & 4.945 & 0.03 & 12.11 & $12290^{* * * *}$ & $-0.026^{* * *}$ & $-13.718^{* * *}$ \\
\hline 801155 & -1.345 & 4.754 & -2.261 & 53.329 & $378124^{* * * *}$ & $0.16^{* * *}$ & $-14.2^{* * *}$ \\
\hline 801156 & -2.577 & 8.67 & -0.426 & 17.912 & $33035^{* * * *}$ & $0.09^{* * * *}$ & $-12.896^{* * * *}$ \\
\hline 801161 & -0.411 & 4.091 & -0.905 & 24.588 & $69499^{* * *}$ & $-0.161^{* * *}$ & $-14.244^{* * * *}$ \\
\hline 801162 & -0.152 & 4.254 & -0.526 & 19.486 & $40411^{* * *}$ & $0.012^{* * *}$ & $-12.533^{* * *}$ \\
\hline 801163 & -0.31 & 5.695 & -0.632 & 23.393 & $61819^{* * *}$ & $-0.038^{* * *}$ & $-15.138^{* * *}$ \\
\hline 801164 & -0.563 & 5.913 & -0.219 & 5.001 & $622^{* * * *}$ & $-0.338^{* * *}$ & $-13.14^{* * * *}$ \\
\hline 801171 & -0.084 & 6.469 & -0.147 & 4.522 & $356^{* * * *}$ & $-0.354^{* * * *}$ & $-13.978^{* * *} *$ \\
\hline 801172 & 0.622 & 6.596 & -0.309 & 20.147 & $43595^{* * *}$ & $-0.274^{* * *}$ & $-14.805^{* * *}$ \\
\hline 801173 & 0.619 & 9.279 & -0.044 & 5.41 & $861^{* * * *}$ & $-0.343^{* * *}$ & $-14.24^{* * * *}$ \\
\hline 801174 & 0.729 & 7.313 & 0.034 & 11.978 & $11938^{* * * *}$ & $-0.076^{* * *}$ & $-12.674^{* * * *}$ \\
\hline 801175 & 0.723 & 3.825 & -0.373 & 6.507 & $1904^{* * * *}$ & $-0.279^{* * *}$ & $-13.566^{* * *}$ \\
\hline 801176 & 1.587 & 8.194 & 0.751 & 12.524 & $13767^{* * * *}$ & $-0.169^{* * *}$ & $-13.217^{* * *}$ \\
\hline 801177 & 0.174 & 8.336 & 0.144 & 5.303 & $797^{* * * *}$ & $-0.403^{* * *}$ & $-15.965^{* * *}$ \\
\hline 801178 & -1.142 & 4.751 & -1.183 & 26.155 & $80226^{* * * *}$ & $-0.044^{* * *}$ & $-14.08^{* * *}$ \\
\hline
\end{tabular}


Asian Economic and Financial Review, 2020, 10(11): 1321-1341

\begin{tabular}{|c|c|c|c|c|c|c|c|}
\hline 801181 & -0.869 & 4.372 & -1.865 & 61.322 & $505764^{* * * *}$ & $0.075^{* * *}$ & $-14.24^{* * * *}$ \\
\hline 801182 & -0.189 & 5.001 & -0.036 & 50.9 & 339765 *** & $-0.117^{* * *}$ & $-13.432^{* * * *}$ \\
\hline 801191 & -0.07 & 6.451 & -0.567 & 23.318 & $61325^{* * *}$ & $-0.087^{* * *} *$ & $-14.984^{* * * *}$ \\
\hline 801192 & -0.726 & 4.571 & 0.141 & 15.213 & $22100^{* * *}$ & $-0.124^{* * *}$ & $-15.312^{* * *}$ \\
\hline 801193 & -0.799 & 6.114 & 1.626 & 58.392 & $455934 * * *$ & $0.08 * * *$ & $-14.999^{* * *} *$ \\
\hline 801194 & -1.106 & 5.455 & 0.029 & 20.385 & $44756^{* * * *}$ & $0.027^{* * *} *$ & $-15.165^{* * * *}$ \\
\hline 801202 & 0.073 & 5.736 & -0.133 & 14.933 & $21097^{* * *}$ & $-0.234^{* * *}$ & -14.441 *** \\
\hline 801203 & 0.529 & 4.123 & -0.237 & 21.943 & $53169 * * *$ & $-0.104 * * *$ & $-13.023^{* * *} *$ \\
\hline 801204 & -0.132 & 6.666 & 0.083 & 10.175 & $7627 * * *$ & $-0.214^{* * *}$ & $-15.7^{* * *} *$ \\
\hline 801205 & 0.129 & 7.235 & 0.473 & 15.382 & $22836^{* * * *}$ & $-0.29^{* * *}$ & $-15.406^{* * * *}$ \\
\hline 801211 & -3.334 & 11.18 & 0.032 & 6.149 & $1469 * * *$ & $-0.199^{* * *}$ & $-15.77^{* * *}$ \\
\hline 801212 & -0.138 & 8.416 & 0.541 & 16.227 & $26081^{* * *} *$ & $-0.216 * * *$ & $-15.32^{* * *} *$ \\
\hline 801213 & 3.7 & 10.659 & 1.261 & 22.761 & $58767^{* * *} *$ & $-0.067^{* * *} *$ & $-13.902^{* * * *}$ \\
\hline 801214 & -1.14 & 9.226 & -0.885 & 34.51 & $147491^{* * * *}$ & $-0.023^{* * *}$ & $-14.829 * * *$ \\
\hline 801222 & -0.788 & 6.87 & -2.365 & 79.895 & $878908^{* * * *}$ & $0.165^{* * *}$ & $-14.683^{* * *} *$ \\
\hline 801223 & 0.796 & 11.852 & 0.029 & 6.514 & $1829^{* * *}$ & $-0.352^{* * *}$ & $-15.129^{* * *} *$ \\
\hline 801231 & -0.16 & 5.522 & -0.291 & 34 & $142354^{* * * *}$ & $-0.1^{* * *}$ & $-14.273^{* * *} *$ \\
\hline 801711 & 1.899 & 8.488 & 3.049 & 77.688 & $831555^{* * * *}$ & $0.12^{* * *}$ & -15.411 *** \\
\hline 801712 & 1.441 & 8.734 & 0.216 & 7.709 & $3311^{* * * *}$ & $-0.252^{* * *}$ & $-15.216^{* * * *}$ \\
\hline 801713 & 0.895 & 5.733 & 0.907 & 22.886 & $59051^{* * * *}$ & $0.016^{* * *}$ & $-15.016^{* * *}$ \\
\hline 801721 & 0.191 & 9.769 & 0.134 & 4.434 & $315^{* * * *}$ & $-0.382^{* * *}$ & $-15.273^{* * *}$ \\
\hline 801722 & 0.785 & 5.303 & -1.06 & 22.936 & $59520^{* * * *}$ & $-0.116 * * *$ & $-16.152^{* * * *}$ \\
\hline 801723 & 0.678 & 5.343 & 0.459 & 15.852 & 24586 **** & $-0.093 * * *$ & $-12.759^{* * *} *$ \\
\hline 801724 & 0.836 & 6.232 & -0.05 & 6.752 & $2086^{* * *}$ & $-0.3^{* * *}$ & $-13.615^{* * *}$ \\
\hline 801725 & -1.986 & 6.082 & -0.631 & 21.37 & $50208^{* * *} *$ & $-0.222^{* * *}$ & $-14.937^{* * * *}$ \\
\hline 801731 & 1.57 & 8.162 & -0.619 & 18.209 & $34482^{* * * *}$ & $-0.108^{* * *}$ & $-15.183^{* * *} *$ \\
\hline 801732 & 0.149 & 6.248 & -0.255 & 12.16 & $12463^{* * *}$ & $-0.045^{* * *}$ & $-14.955^{* * * *}$ \\
\hline 801733 & 2.507 & 6.899 & 6.863 & 213.396 & $6583022^{* * *}$ & $0.032^{* * *}$ & $-14.506^{* * * *}$ \\
\hline 801734 & -0.391 & 4.735 & -1.798 & 57.386 & $439925^{* * * *}$ & $-0.015 * * *$ & $-14.019^{* * * *}$ \\
\hline 801741 & 1.939 & 5.806 & 2.174 & 50.854 & $341915^{* * *}$ & $-0.065^{* * *}$ & $-14.438^{* * * *}$ \\
\hline 801742 & 1.342 & 4.438 & -0.222 & 13.912 & $17663^{* * *}$ & $0.096^{* * *}$ & $-13.931^{* * *} *$ \\
\hline 801743 & 1.086 & 5.518 & 0.065 & 16.33 & $26314 * * *$ & $-0.145 * * *$ & $-15.402 * * *$ \\
\hline 801744 & -0.54 & 9.756 & 0.483 & 98.549 & $1352077^{* * * *}$ & $-0.143^{* * *}$ & $-16.34^{* * * *}$ \\
\hline 801751 & -0.737 & 8.929 & -0.352 & 7.031 & $2480^{* * *} *$ & $-0.176^{* * *}$ & $-14.61^{* * *}$ \\
\hline 801752 & 1.823 & 7.355 & -1.207 & 45.102 & $263352^{* * * *}$ & $0.132^{* * *}$ & $-13.324^{* * * *}$ \\
\hline 801761 & -1.072 & 4.977 & -1.975 & 36.741 & $170898 * * *$ & $0.034^{* * * *}$ & $-13.108^{* * * *}$ \\
\hline 801881 & 0.67 & 7.784 & 0.006 & 7.847 & $3479^{* * * *}$ & $-0.189^{* * *} *$ & $-15.836^{* * * *}$ \\
\hline
\end{tabular}

Views and opinions expressed in this article are the views and opinions of the author(s), Asian Economic and Financial Review shall not be responsible or answerable for any loss, damage or liability etc. caused in relation to/arising out of the use of the content. 